\title{
REORIENTASI LGBT DI INDONESIA (STUDI FIQH AL-HADITS)
}

\author{
Mahdalena Nasrun \\ Universitas Islam Negeri Ar-Raniry Aceh \\ Jl. Syeikh Abdul Rauf, Kopelma Darussalam, Syiah Kuala, Kota Banda Aceh \\ e-mail: happlen8@gmail.com
}

\begin{abstract}
Liberal NGOs such as Ardhanary Institute, Gaya Nusantara and Arus Pelangi devoted their body for LGBT with a statement "my body is mine, not the one who has the right to govern my body, not the parents, the state, and even the religion". This movement is disturbing the community. The research question of the study was how did LGBT exist in Indonesia? And how does fiqh al hadith view about LGBT. This study used normative legal research. The result of this study revealed that the existence of LGBT in Indonesia in its history. Probibition and punishment have been explained in the book of Tuhfah al Abwaz, the fatawa of MUI (Indonesian Council of Ulama) (1974, 2014) in line with the criminal code article 292 homosexsual acts, article 4 point 1 a of the law on pornography and contradictory to article 1 of law № 1 of 1974 about marriage.
\end{abstract}

Kata kunci: orientasi, LGBT, fiqh al hadits

\section{PENDAHULUAN}

$\mathcal{M}$ araknya perbincangan LGBT sekarang bisa dibaca di surat kabar seperti harian serambi dalam opini yang berjudul Mewaspadai Aliran LGBT di Aceh, dan opini yang bertajuk LGBT Berjubah Demokrasi. Perbicangan juga bisa didengar melalui talkshow di radio ataupun bisa disaksikan melalui siaran TV lokal dan nasional. Menurut Nasrullah mengutip Laporan Nasional Indonesia UNDP yang berjudul Hidup Sebagai LGBT di Asia bahwa sebenarnya istilah LGBT bukanlah baru pertama kali ini tetapi telah populer sekitar era 1990-an. Sampai akhir tahun 2013 terdapat dua jaringan nasional organisasi LGBT yang terdiri dari 119 organisasi berlokasi di 28 provinsi dari 34 provinsi di Indonesia. Komunitas LGBT yang paling terkenal adalah Organisasi
LGBT Arus Pelangi di Jakarta dan Gaya Nusantara di Surabaya. Lebih banyak organisasi bercokol di pulau-pulau yang berpenduduk lebih padat, khususnya pulau Jawa dan Sumatera. Sedangkan di pulau Kalimantan dan Sulawesi serta di Kawasan Indonesia Timur pada umumnya, terdapat lebih sedikit organisasi. (Nasrullah el-Jabouny, 2016: t.h.)

Kelompok LGBT sekarang lebih berani mempublikasikan dirinya melalui media cetak maupun elektronik, melakukan demonstrasi di bundaran $\mathrm{HI}$ dan orasi di acara Car free day. Gerakan ini seperti jamur di musim hujan yang meresahkan sehingga diperlukan pemikiran, tindakan yang bijak untuk mencarikan solusinya, karena kita berbangsa negara Indonesia bukan atas satu agama. 
2 || Jurnal Inmiah Sygari'ah, Volume l6, Nomor I, Jantuari-Juni 2001"

Dalam Islam pembagian gender biasanya dipetakan menjadi empat: lakilaki, perempuan, khuntsa (hermaprodit), dan mukhannits atau mukhannats. Mukhannits adalah laki-laki biologis yang mengidentifikasikan diri sebagai perempuan dan menginginkan pergantian seks. Sedangkan mukhannats adalah laki-laki biologis yang berartribut perempuan tapi tidak menginginkan pergantian seks biologisnya. Baik istilah mukhannits atau mukhannats tidak disebutkan di dalam Alquran. (Moh. Yasir, 2004: xii) Penjelasan Rasulullah saw berbunyi:

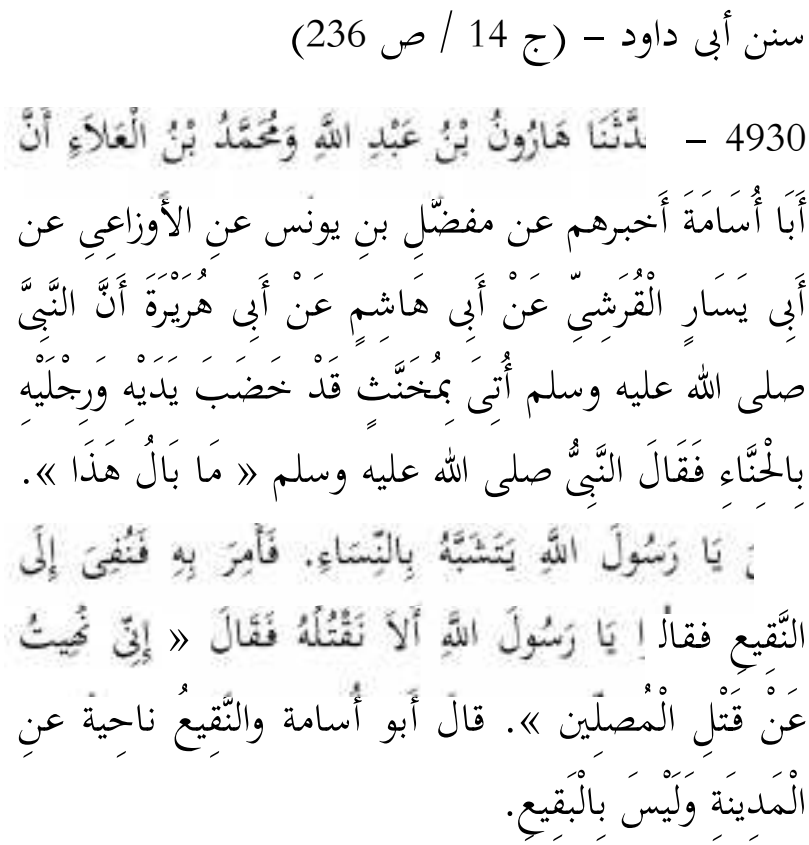

Artinya: Harun bin Abdullah dan Muhammad bin al-'Ala $i$ menceritakan kepada kami bahwa Abu Usamah memberi kabar kepada kami dari Mufadhalah bin Yunus dari al-Auza'i dari Abu Yasar alQurasyi dari Abu Hasyim dari Abu Hurairah ra: kepada Nabi saw seorang lakilaki yang menyerupai wanita. Laki-laki itu telah mewarnai tangan dan kakinya dengan pacar. Nabi saw bertanya ada apa dengan orang ini? Seseorang menjawab, wahai Rasulullah, orang ini telah berpenampilan menyerupai perempuan. beliau pun memerintahkan agar laki-laki itu diasingkan di daerah an-Naqi'. Lalu seseorang bertanya, 'wahai Rasulullah, tidakkah lebih baik kita membunuhnya? Beliau menjawab, aku dilarang membunuh orang-orang yang menegakkan shalat. Abu Usamah berkata, An-Naqi' adalah sebuah wilayah di Madinah bukan al-Baqi'.

Hadis di atas menjelaskan larangan laki-laki yang menyerupai perempuan dari cara bergaya, berbicara, bertingkah laku. Faris Malik mengungkapkan sebagaimana yang dikutip oleh Moh Yasir Alimi bahwa Alquran secara eksplisit mengakui adanya orang yang bukan laki dan bukan perempuan. Ayat [42]: 49-50 diterjemahkan sebagai berikut: "hanya milik Tuhanlah segala yang ada di langit dan di bumi. Tuhan menciptakan apa yang ia kehendaki. Ia menyiapkan yang ia kehendaki menjadi perempuan dan menyiapkan yang ia kehendaki menjadi laki-laki dan perempuan dan ia juga menciptakan orang tidak berketurunan yang ia kehendaki. Menurutnya terjemahan bahwa Tuhan 'memberikan anak perempuan atau anak laki-laki yang ia kehendaki dan memberikan yang ia kehendaki baik anak laki-laki maupun anak perempuan sekaligus' sangat problematik. (Moh. Yasir, 2004: xv)

Ayat ini menurut Faris mendeskripsikan pengakuan Alquran terhadap beragamnya orientasi seksual dan gender. Ia juga mencatat bahwa tafsir atas surat [13]: 3 yang menunjukkan pada setiap buahbuahan diciptakan berpasang-pasangan' juga mengakui adanya seks ketiga dalam Islam. Cendikiawan ini juga menegaskan kemungkinan adanya seks ketiga dalam dunia binatang dan manusia, bila seks semacam itu ada pada dunia tumbuhan. Bagaimana halnya dengan hadis yang 
melarang transgender? Hadis yang sering dirujuk adalah hadis riwayat Ummu Salamah r.a. (Moh. Yasir, 2004: xiv-xvi)

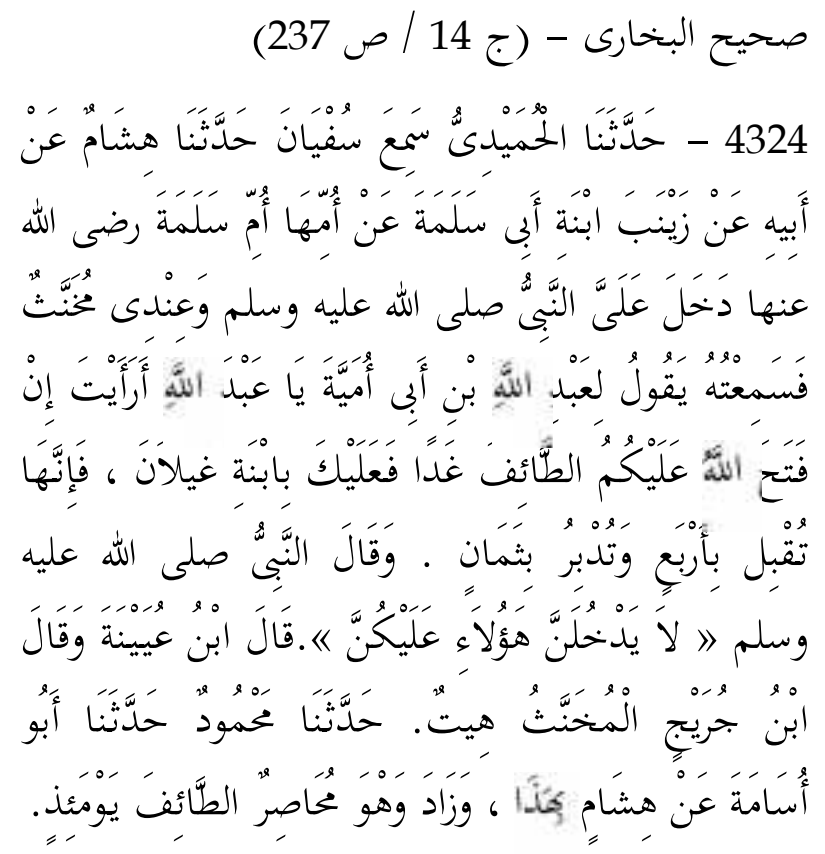

Artinya: al-Humaid menceritakan kepada kami Sufyan menceritakan kepada kami Hisyam menceritakan kepada kami dari ayahnya dari Zainab binti Abu Salamah dari ibunya Ummi Salamah: berkata Nabi saw masuk menemuiku saat aku sedang bersama seorang waria. Aku mendengar dia berkata kepada Abdullah bin Umayyah, wahai Abdullah, jika besok Allah memberi kalian kemenangan dalam menaklukkan Thaif, engkau harus mendapatkan putri Ghailan karena dari delapan lipatan kulitnya ada empat, sedangan dari belakang ada delapan (tubuhnya sintal); Nabi saw bersabda jangan ada dari mereka (kaum waria) yang masuk menemui kalian. Abu Uyainah mengatakan bahwa Ibnu Juraij berkata, waria itu bernama Hit. Mahmud menceritakan kepada kami dari Abu Usamah dari Hisyam dengan tambahan, "ketika dia sedang mengepung Thaif.

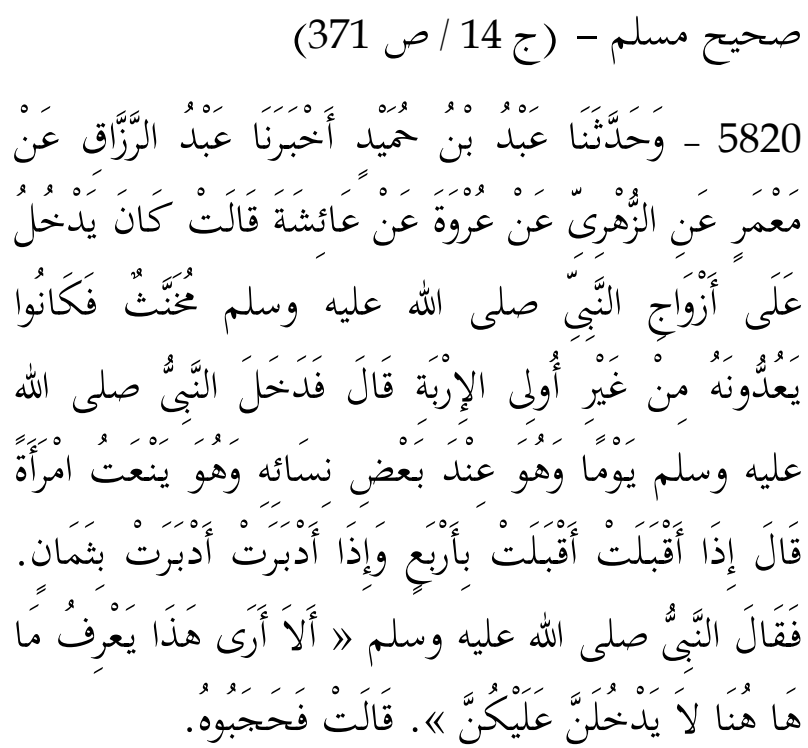

Artinya: 'Abdullah bin Humaid menceritakan kepada kami 'Abdu al-Razaq memberi kabar kepada kami dari Ma'mar dari al-Zuhri dari 'Urwah dari 'Aisyah berkata suatu ketika seorang banci masuk ke tempat para isteri Nabi saw. mereka menganggapnya seperti orang yang tidak mempunyai nafsu birahi terhadap wanita. Kemudian Nabi saw datang. Saat itu si banci tersebut sedang berada di antara mereka sambil menyifatkan seorang wanita, dia berkata, 'bila menghadap, dia menghadap dengan empat lipatan perutnya; bila membelakangi, dia membelakangi dengan delapan lipatan perutnya. Lantas Nabi saw bersabda, perhatikan bukankah dia mengerti apa yang ada di sini (seputar wanita dan keindahannya)? Karena itu, jangan kalian izinkan dia masuk ke rumah kalian. setelah itu mereka tidak mengizinkan.

Menurut Faris Malik, pelarangan ini sebenarnya bukan pada penolakan atas transgender atau banci sendiri melainkan penolakan terhadap laki-laki yang berpura-pura menjadi banci dan masuk dalam ruang privasi perempuan. Seperti 
diketahui, Alquran mengakui bahwa beberapa laki-laki "tidak mempunyai kemampuan sebagai laki-laki (Q.S. [24]: 31) atau ghairi li al-irtibati min al-rijali dan oleh karenanya dalam fiqh, sebagai pembantu rumah tangga diizinkan untuk melihat perempuan telanjang. Sementara laki-laki yang diceritakan oleh Ummu Salamah adalah laki-laki yang tahu tentang perempuan yang cantik, sehingga tidak bisa dikategorikan sebagai ghairi $l i$ al-irbati min al-rijali. (Moh. Yasir, 2004: xvii) Ini juga terlihat dari hadis yang sama diriwayatkan oleh 'Aisyah di atas. Firman Allah Swt dalam Q.S. al-'Araf [7]: 81 berbunyi:

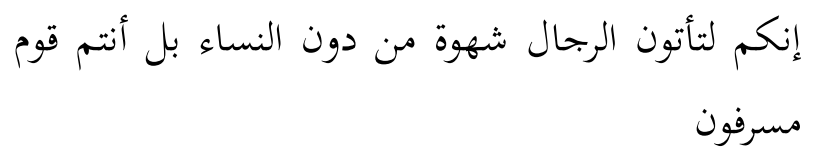

Artinya: Sesungguhnya kamu mendatangi lelaki untuk melepaskan nafsumu (kepada mereka), bukan kepada wanita, malah kamu ini adalah kaum yang melampaui batas.

Dalam sejarah komunitas transgender sudah ada di daratan Sulawesi sejak ratusan tahun yang lalu bahkan sebelum Islam. Bagi bissu, seperti dicatat Bisri Efenddi dan Ijhal Thamaona dalam Srinthil (edisi 5/2003), 'bukan laki-laki dan bukan perempuan adalah identitas yang sangat jelas. 'semua kelompok adat dan sebagian besar masyarakat Sulawesi Selatan "menganggap identitas bissu sebagai wajar-wajar saja dan merupakan ciptaan Tuhan. Sebagian besar bissu adalah muslim dan menjadi bissu yang pada masa lalu diyakini sebagai penghubung manusia dengan dewa tidak menghalangi mereka untuk menjadi muslim yang baik karena mereka yakin keislaman tidak ditentukan dengan jenis kelamin dan orientasi seksual. (Moh. Yasir, 2004: xxxii)

Dalam kesehariannya bissu berpenampilan layaknya perempuan. sehingga tidak mudah membedakan mana bissu yang laki-laki dan mana bissu yang perempuan. Realitas ini menjadikan bissu dianggap tidak menerima sunnatullah, karena merasa lakilaki tapi berpenampilan seperti perempuan. Bissu juga dianggap menyimpang dari agama (dalam hal ini agama Islam), misalnya mereka dikatakan menyembah berhala. Padahal mereka melakukan pemujaan terhadap Tuhan sesuai dengan tatacara agama yang mereka yakini. (Halilintar Lathief, 2004: v)

Sehubungan dengan heteronormativitas adalah ideologi yang mengharuskan lakilaki dan perempuan tunduk pada aturan heteroseksualitas yang intinya adalah keharusan fungsi pro-kreasi seksualitas. Dalam aturan ini, agar bisa bereproduksi, maka perempuan harus berpasangan dengan laki-laki dan sebaliknya. Laki-laki dan perempuan oleh karenanya dibedakan secara ketat identitas seks dan peran gendernya. Bila perempuan, maka harus feminim dan bila laki-laki harus maskulin. Identitas keduanya tidak boleh dicampuradukkan. Inilah yang menjelaskan mengapa semua bentuk praktik seksual seperti relasi seksual sejenis dan onani-yang tidak berorientasi prokreasi diharamkan. Juga yang menjelaskan mengapa perempuan atau laki-laki yang tidak bisa bereproduksi dianggap sebagai perempuan dan lakilaki yang tidak ideal. Ini pula yang menjelaskan mengapa waria yang dianggap mengacaukan identitas gender juga direpresi.

Sebaliknya sebuah premis bahwa hegemoni heteronormatif yang membentuk gagasan-gagasan tentang seksualitas yang 
selama ini dianggap normal perlu dipertanyakan dan diguncang (destabilized). Pembongkaran ini perlu dilakukan karena sesungguhnya seksualitas normatif maupun seksualitas non-normatif adalah sebuah konstruksi sosial. (Saskia E. Wieringa, dkk., 2007: xi) Jadi khususnya untuk sistem heteronormativitas adalah menekankan pada hubungan sosial hetero atau antara lelaki dan perempuan yang tidak baik, tidak wajar, tidak alami menyimpang atau abnormal dll.

Dalam norma gender yang dominan, baik maskulinitas maupun femininitas, terdapat bentuk-bentuk gender lainnya yang bersifat non-hegemonik seperti waria, banci, gay, homo, tomboi, lesbian, hijra (India), perempuan maskulin, lakilaki feminim dll. Inilah yang disebut sebagai gender non-normatif yang seringkali mengalami tekanan dan pembisuan oleh lingkungan sosial yang heteronormatif. Oleh karena itu, menjadi penting untuk memahami bagaimana hegemoni gender yang dominan dikonstruksikan, dilanggengkan dan diwariskan melalui berbagai elemen seperti agama, ekonomi, politik, media, keluarga, pendidikan dll.

Dalam konteks masyarakat modern dan era globalisasi ini peran media massa tidak dapat diabaikan. Koran, majalah, $\mathrm{TV}$, radio, internet semakin menjadi bagian penting dari kehidupan seharihari. Media pun seringkali menjadi sarana mereproduksi nilai-nilai sosial yang hegemonik. Ideologi heteronormativitas secara terus menerus diproduksi melalui teks yang berbeda-beda. Teks media merepresentasikan norma dan nilai dominan yang dianut dan dianggap benar oleh masyarakat. Teks media menjadi penting dicermati karena ia merupakan representasi nilai dan pendapat kelompok dominan itu, misalnya bagaimana lesbian dianggap sebagai penderita penyakit jiwa atau kelainan kepribadian seperti terlihat dalam rubrik seksologi atau kolom konsultasi di majalah-majalah atau koran. Tak satu pun ahli/psikologi psikiatris yang menjaga rubrik konsultasi itu yang menginformasikan bahwa sejak tahun 1981, WHO telah mengeluarkan homoseksualitas dari daftar sebagai penyakit jiwa dan pada tahun 1992 mengeluarkannya dari daftar klasifikasi penyakit (international classification diseases). (Saskia E. Wieringa, dkk., 2007: xix)

Gerakan LGBT yang melancarkan tekanan kepada pihak-pihak yang menolak mereka dengan tudingan melanggar HAM. LSM liberal seperti Ardhanary Institute, Gaya Nusantara, dan Arus Pelangi bahkan mewacanakan tubuh bagi kaum homo dan transgender dengan pemahaman "tubuhku adalah milikku, tidak ada yang berhak mengatur tubuhku, apalagi orang tua, negara, bahkan agama". Kebebasan gay juga didukung slogan "cinta tidak mengenal hukum". (Fahmi Salim, 2013: 27)

Ketua MPR RI Zulkifli Hasan secara tegas menolak gerakan LGBT, Majelis Ulama Indonesia (MUI) juga menegaskan menolak segala bentuk propaganda, promosi, dan dukungan terhadap legislasi dan perkembangan Lesbian, Gay, Biseksual, dan Transgender (LGBT) di Indonesia. (http: www//Lia Wanadriani Santosa.) Penolakan juga ditegaskan oleh Ma'ruf Amin sebagai Ketua Umum MUI. (http:www/ / Abba Gabrillin) 


\section{METODE PENELITIAN}

\section{Jenis Penelitian}

Penelitian yang digunakan yaitu penelitian hukum normatif. Artinya penelitian hukum yang meletakkan hukum sebagai sebuah bangunan sistem norma. Sistem norma yang dimaksud adalah mengenai asas-asas, norma, kaidah dari peraturan perundangan, putusan pengadilan, perjanjian serta doktrin (ajaran). (Mukti Fajar dan Yulianto Achmad, 2010: 34)

Bahan-bahan hukum primer terdiri dari perundang-undangan, catatancatatan resmi atau risalah dalam pembuatan perundang-undangan dan putusan-putusan hakim. (Peter Mahmud Marzuki. 181). Bahan hukum primer yang dimaksud di sini adalah kutub al-hadis, Fatwa MUI Nomor 57 Tahun 2014.

Bahan hukum sekunder yang memberikan penjelasan mengenai bahan hukum primer, seperti misalnya rancangan undang-undang, hasil-hasil penelitian, hasil karya dari kalangan hukum dan seterusnya. (Soerjono Soekanto, 2004: 52). Dalam penelitian ini menggunakan buku berjudul Hegemoni Hetero-Normativitas Membongkar Seksualitas Perempuan yang Terbungkam.

Bahan hukum tertier, yakni bahan hukum yang memberikan petunjuk maupun penjelasan terhadap bahan hukum primer dan sekunder; contohnya adalah kamus, koran, tulisan atau penelitian orang lain yang berasal dari internet dan seterusnya. Dalam hal penelitian ini menggunakan Kamus Besar Bahasa Indonesia.

\section{Teknik Pengumpulan Data}

Ronny Hanitijo mengungkapkan teknik pengumpulan data yang dikutip oleh Mukti Fajar bahwa dalam penelitan hukum normatif atau kepustakaan dilakukan dengan studi pustaka terhadap bahan-bahan hukum, baik bahan hukum primer, bahan hukum sekunder, maupun bahan hukum tersier dan atau bahan hukum non-hukum. Penelusuran bahanbahan hukum tersebut dapat dilakukan dengan membaca, melihat, mendengarkan, maupun sekarang banyak dilakukan penelusuran bahan hukum tersebut dengan melalui media internet.

Dalam penelitian hukum normatif, pengolahan bahan berujud kegiatan untuk mengadakan sistematisasi terhadap bahan-bahan hukum tertulis. Dalam hal ini pengolahan bahan dilakukan dengan cara, melakukan seleksi data sekunder atau bahan hukum, kemudian melakukan klasifikasi menurut penggolongan bahan hukum dan menyusun data hasil penelitian tersebut secara sistematis, tentu saja hal tersebut dilakukan secara logis, artinya ada hubungan dan keterkaitan antara bahan hukum satu dengan bahan hukum lainnya untuk mendapatkan gambaran umum dari hasil penelitian.

\section{Teknik Analisis Data}

Analisis data merupakan kegiatan dalam penelitian yang berupa melakukan kajian atau telaah terhadap hasil pengolahan data yang dibantu dengan teori-teori yang telah didapatkan sebelumnya. Secara sederhana analisis data ini disebut sebagai kegiatan memberikan telaah yang dapat berarti menentang, mengkritik, mendukung, menambah atau memberi komentar dan 
kemudian membuat suatu kesimpulan terhadap hasil penelitian dengan pikiran sendiri dan bantuan teori yang telah dikuasai. Adapun sifat analisis data yang digunakan deskriptif untuk memberikan gambaran atau pemaparan atas subjek dan objek penelitian. sifat evaluatif yaitu memberikan penilaian dari hasil penelitian, apakah hipotesis dari teori hukum yang dilakukan diterima atau ditolak. Dan bersifat preskriptif yaitu memberikan argumentasi atas hasil penelitian yang telah dilakukan. (Mukti Fajar dan Yulianto Achmad, 2010: 160183). Dalam hal ini juga memakai analisis isi (content analysis) yaitu teknik penelitian untuk membuat inferensi-inferensi yang dapat ditiru (replicabel), dan sahih data dengan memperhatikan koteksnya. (Burhan Bungin (ed), 2007: 231)

\section{PEMBAHASAN}

\section{Pengertian LGBT}

LGBT adalah singkatan dari lesbian, gay, biseksual dan transgender. Lesbian dalam kamus besar bahasa Indonesia diartikan sebagai wanita yang cinta birahi kepada sesama jenisnya; wanita homoseks. (Tim. 820) Biseksual didefinisikan sebagai 1. Mempunyai sifatsifat kedua jenis kelamin (laki-laki dan perempuan); 2. Tertarik kepada kedua jenis kelamin (baik kepada laki-laki maupun kepada perempuan). (Tim. 199). Trans diartikan sebagai 1 . Bentuk morfem yang terikat yang diimbuhkan pada bagian awal yang bermakna melintasi, melalui, 2. Keadaan seseorang terputus hubungan nya dengan sekelilingnya (seperti waktu meditasi,berkhayal). (Tim.
959). Gender adalah jenis kelamin. (Tim. 439) Jadi maksudnya adalah bertukar kelamin melalui operasi.

Dalam kajian Islam dikenal dengan istilah khuntsa yaitu orang yang memiliki sekaligus apa yang dimiliki oleh laki-laki dan perempuan. berdasarkan pengertian ini maka khuntsa sama dengan banci, karena Mursal dalam kamus Ilmu Jiwa dan Pendidikan mengatakan: "banci yaitu orang yang memunyai dua macam jenis kelamin hingga ia mempunyai sikap rangkap antara laki-laki dan perempuan secara jasmaniah dan rohaniah. (Huzaimah Tahido Yanggo, 2005: 198)

Adapun hubungan seks antara sesama lelaki dengan cara liwath maupun mufakhadzah, para ulama sepakat hukumnya haram, bahkan dianggap sebagai perilaku yang sangat jijik, keji, dan melebihi hewan. Hubungan seks antara sesama perempuan yang disebut musahaqah, para ulama sepakat pula keharamannya dan sepakat mengenai sanksinya, cukup dengan ta'zir. Pada dasarnya para ulama berpendapat haram melakukan hubungan seks antara lelaki atau sesama perempuan atau yang tidak lazim dan tidak wajar. (Sahal Mahfudh. 89)

\section{Keberadaan LGBT di Indonesia}

Snouck menceritakan bahwa praktek homoseks cukup meluas. Di Aceh Besar, sekedar kepatuhan masih dipatuhi mengenai praktek paederasti dan para homoseks tidak secara terbuka mengakui obyek nafsu yang tidak sesuai dengan hukum agama, walaupun tetangga mereka bisa saja mengetahui semua itu. Tetapi di Pidie dan Pantai Timur dan Barat, orang sering tak kenal malu 
memunculkan diri di depan umum bersama pasangannya. Orang Aceh sering diejek di Penang bila kelihatan berjalanjalan dengan pria remaja di jalanan, dan orang baik-baik sering mengacaukannya dengan orang yang salah; misalnya bila disertai anak laki-laki ataupun adiknya. (Snouck Hurgronje, 1985: 23)

Sebaliknya, kejahatan ini sama sekali bukan monopoli masyarakat Aceh. Ia banyak ditemukan dalam buku-buku lama agama Islam. Perilaku ini ada disebut dalam sastra Arab, dan Mekkah sekarang tidak kalah reputasinya mengenai hal ini dibanding Kairo atau Konstantinopel. Praktek homoseks juga ada ditemukan di Jawa, khususnya kelompok-kelompok pribumi dan hal yang sama juga dapat disebutkan mengenai Minangkabau di Sumatera. Namun hanya di Aceh ditemukan perbedaan interpretasi pepatah Eropa tentang moralitas praktis sebagai "menabur gandum liar" dalam pengertian bahwa sejumlah kejahatan yang tidak wajar merupakan suatu tahap yang diperlukan dalam perkembangan setiap pemuda. Seorang Aceh yang berperadaban tinggi, yang standar moralnya jauh lebih unggul daripada rakyat banyak, mengutarakan kepada saya dengan bahasa sederhana bahwa masyarakat Aceh memegang pandangan serupa itu. (Snouck Hurgronje, 1985: 23). Praktik ini juga dilakukan di di Sulawesi Selatan, Jawa Tengah, Papua dan Ponorogo.

Di Sulawesi Selatan kaum bissu memiliki klasifikasi sendiri tentang calabai. Ada tiga tingkatan calabai yang mereka akui, yaitu: tingkatan pertama calabai tungke'na lino (yaitu calabai yang berhak menyandang dan menamai dirinya bissu), kedua pancalabai (di kalangan remaja Segeri, Pangkep, dikenal dengan istilah "maju kena mundur kena" atau "AC-DC", yang maksudnya adalah calabai yang bisa berhubungan dengan pria maupun wanita), ketiga calabai kedo-kedonami atau calabai yang hanya meniru gayanya saja. Menurut para bissu, calabai yang seperti ini sangat berbahaya karena sebenarnya mereka adalah pria tulen. Mereka bergaya menyerupai wanita (calabai) sehingga mudah memperdaya wanita. (Halillintar Lathief, 2004: 39)

Dahulu, perbedaan antara bissu dan calabai ditandai antara lain dengan tidak bolehnya para bissu pacaran atau kawin. Namun sepuluh tahun terakhir ini diperoleh data bahwa ada bissu yang membangun rumah tangga dengan seorang istri sebagai pasangan hidupnya. Selain itu, saat ini seorang bissu kadang juga mempunyai seorang pasangan hidup pria muda yang dalam istilah bissu toboto. (Halillintar Lathief, 2004: 57-59)

Sebelum Islam, fungsi upacara bissu mendapat kedudukan penting dalam masyarakat. Pada masa lampau, pelaksanaan upacara ritual mappalili yang dipelopori oleh kaum bangsawan dan hartawan Bugis di Segeri. Yang kemudian setelah Islam dianut oleh orang Bugis didukung dengan gerakan pemurnian ajaran Islam disebut "operasi Toba" (operasi taubat) yang sangat gencar dilakukan pada tahun 1966 sejak saat itu upacara mappalili mengalami kemunduran, upacara-upacara bissu tidak lagi diselenggaran secara besar-besaran. Sebagian masyarakat berpendapat bahwa bissu saat ini hanya sebagai perhiasan saja, dalam arti keberadaannya kini masih dirasakan kehadirannya namun dianggap tidak ada lagi. Hidup tidak, mati pun tak 
rela. Kedudukan fungsi dan kualitas bissu makin menyusut dari hari ke hari. (Halillintar Lathief, 2004: 68-82)

Ritual itu juga dilakukan petani Jawa Tengah, kelompok etnis Papua, demi mendatangkan kesuburan di sawahsawah mereka. Penyimpangan lain terjadi di Gunung Kemukus, Sragen, Jawa Tengah ada sebuah makam yang dianggap sakral. Orang berziarah ke sana mencari berkah untuk mendapatkan keberuntungan, kenaikan jabatan, menang lotre atau mendapatkan pasangan baik untuk dinikahi. Namun salah satu syaratya adalah melakukan hubungan seks dengan orang yang tidak dikenal. Ritual di Gunung Gangsir mirip dengan Gunung Kemungkus, lokasinya di tanggara Surabaya. Pasangan-pasangan yang telah menikah masih suka pergi ke sana pada hari-hari tertentu sesuai penanggalan Jawa. Masing-masing suami atau isteri lalu pergi sendiri-sendiri mencari suami atau isteri orang lain untuk melakukan hubungan seks, lalu mereka bergabung kembali dengan suami atau isteri mereka sendiri, dan keberuntungan bisnis mereka pun menjadi baru kembali. Ritual itu kini lebih bervariasi yaitu heteroseksual, homoseksual, laki-laki dan waria, ritual tersebut dilakukan di sebuah pemakaman di dekat reruntuhan candi Hindu-Budha yang diagungkan (Candi Gunung Gangsir) dan berbau ritual Tantra yang penuh gejolak seks bebas. Ini tidak mengherankan, karena Singasari-dinasti kuno yang pernah menguasai daerah tersebut-menganut aliran tantra. (Julia Suryakusuma, 2012: 410)

Penyimpangan terjadi juga di Ponorogo, sebuah kota keci di Jawa Timur, tempat warok, sebutan bagi laki- laki yang membawakan tarian-tarian ritual untuk membawa keberuntungan bagi masyarakat. Para penarinya yang disebut gemblak, adalah anak-anak lelaki tampan, berumur antara 10-16 tahun. Sang Warok melakukan hubungan seks dengan gemblaknya untuk memelihara kekuatan mistisnya sesungguhnya ini adalah pedofilia yang dilembagakan. Tidak heran kemudian pemerintah menyuruh para warok mengubah perilakunya. Kini kelompok-kelompok tari diisi gadis-gadis, sementara para gemblak semua bergabung dalam komunitas-komunitas gay di kota-kota besar. (Julia Suryakusuma, 2012: 411)

Kenyataan ini tentu sangat memprihatinkan, keberadaan LGBT tidak bisa ditutupi tetapi bukan berarti pasrah begitu saja dan seyogyanya sebagai masyarakat Islam terbesar di dunia, melaksanakan tugas amar ma'ruf nahi mungkar.

\section{Fiqh al-Hadis dalam Wacana LGBT}

Hadis-hadis yang menceritakan LGBT terdapat dalam kitab hadis (1) Sunan Ibn Majah no 2660, 2658, 2659. (2). Musnad Ahmad ibn Hanbal no 2779. (3). Sunan Abi Dawud no 4464. (4). Sunan atTirmidzi no 1528, 1529 berikut ini:

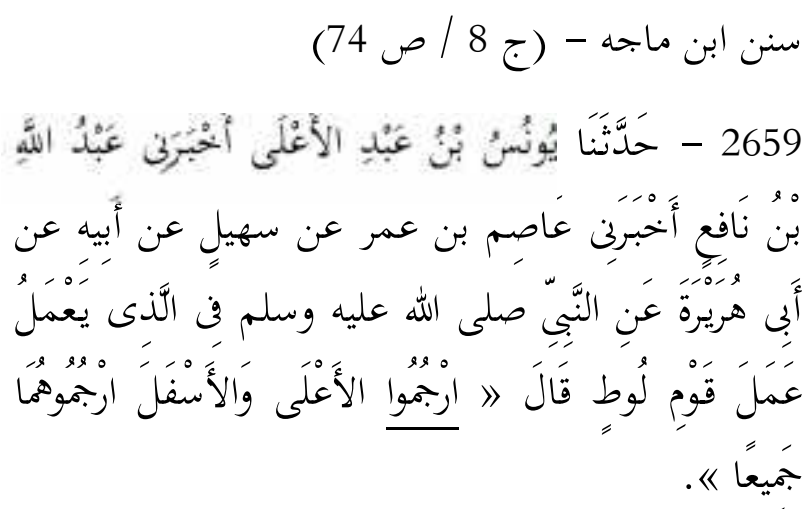


Artinya: Yunus bin 'Abdi al-'Ala menceritakan kepada kami 'Abdullah bin Nafi' mengabariku 'Ashim bin 'Umar mengabariku dari Suhail dari ayahnya dari Abu Hurairah dari Nabi saw mengenai perbuatan kaum Nabi Luth bersabda rajamlah orang yang melakukan perbuatan kaum Luth (liwath), (pelaku) dan (partner)nya, rajamlah semuanya.

$$
\text { سنن ابن ماجه - (ج } 8 \text { / ص 73) }
$$

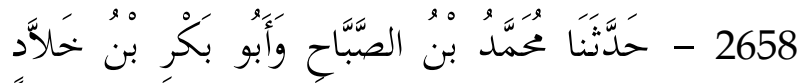

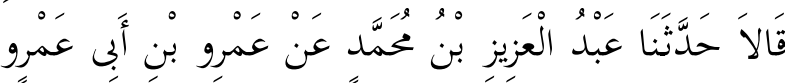

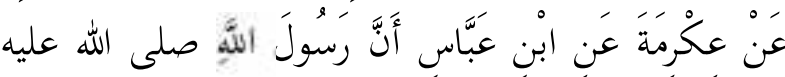

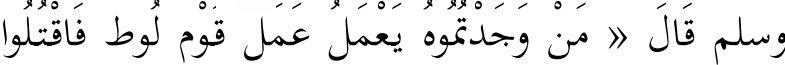

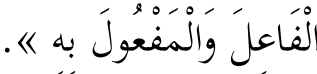

Artinya: Telah menceritakan kepada kami Muhammad bin al-Shabbah dan Abu Bakr bin Khallad berkata telah menceritakan kepada kami 'Abdul al-'Aziz bin Muhammad dari 'Amr bin bin Abi 'Amr dari 'Ikrimah dari Ibnu 'Abbas sesungguhnya Rasulullah saw bersabda barang siapa yang kalian mendapati melakukan perbuatan kaum Luth (liwath), maka bunuhlah fa'il (pelaku) dan maf'ul bih (partner)nya.

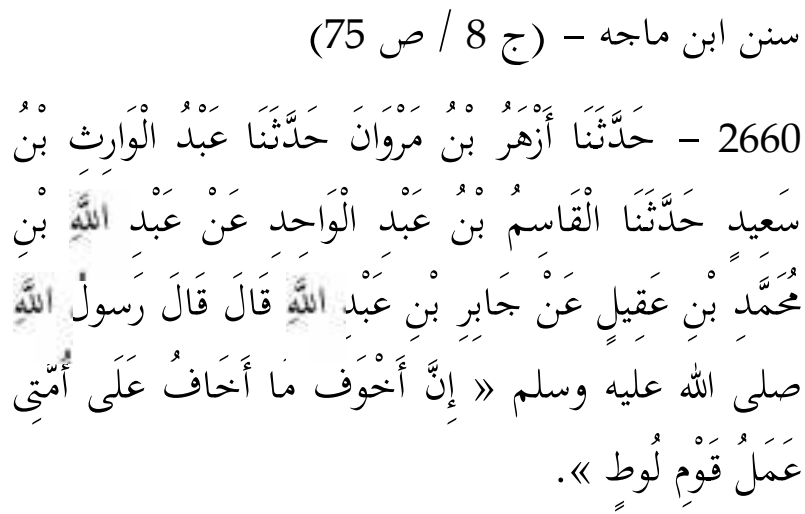

Artinya: Azhar bin Marwan menyampaikan kepada kami 'Abdu al-
Waris bin Sa'id menyampaikan kepada kami al-Qasim bin 'Abdi al-Wahid menyampaikan kepada kami dari 'Abdillah bin Muhammad bin 'Aqil dari Jabir bin 'Abdillah berkata telah mendengar Rasulullah saw bersabda sesunggunya aku takut akan tertimpa musibah umatku karena perbuatan kaum Nabi Luth.

$$
\text { مسند أحمد - (ج } 6 \text { / ص 305) }
$$

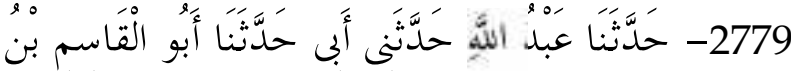

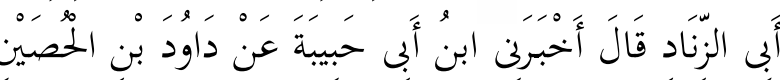

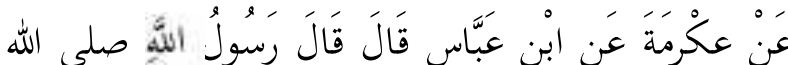

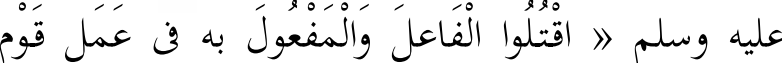

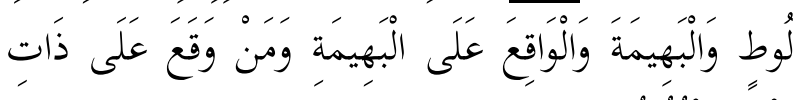

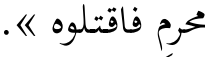

Artinya: 'Abdullah menyampaikan kepada kami ayahku menyampaikan kepadaku Abu al-Qasim bin Abi az-Zinad menyampaikan kepada kami berkata ibn Abi Habibah mengabariku dari Dawud bin alHusain dari 'Ikrimah dari Ibn 'Abbas berkata Rasulullah saw bersabda bunuhlah pelaku dan partner orang yang melakukan perbuatan kaum Luth (liwath), dan yang melakukannya kepada binatang dan yang melakukan terhadap zat yang diharamkan maka bunuhlah.

$$
\text { سنن أبى داود - (ج } 13 \text { / ص 131) }
$$

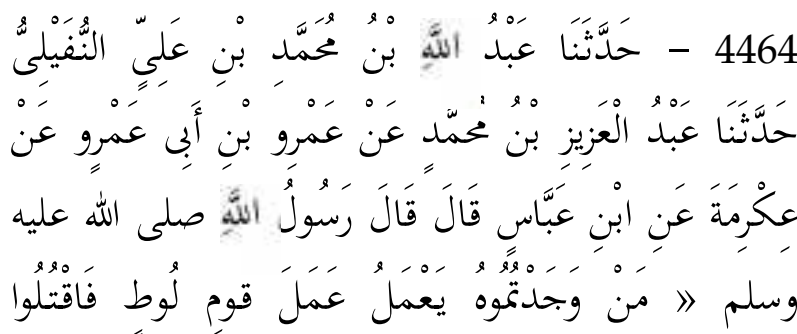

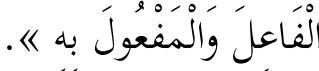


Artinya: 'Abdullah bin Muhammad bin 'Ali an-Nufaili menyampaikan kepada kami 'Abdu al-'Aziz bin Muhammad menyampaikan kepada kami dari 'Amr bin Abi 'Amr dari 'Ikrimah dari ibn 'Abbas berkata Rasulullah saw bersabda barang siapa yang mendapati perbuatan kaum Nabi Luth maka bunuhlah pelaku dan partnernya...

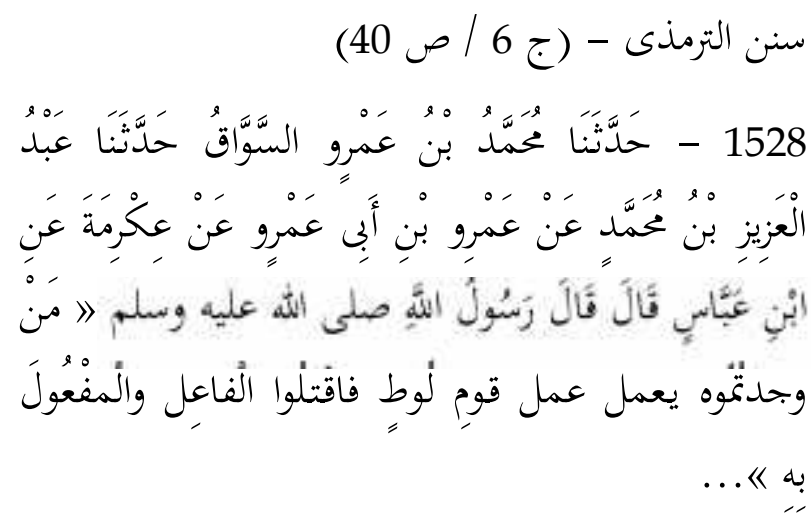

Artinya: Muhammad bin 'Amrin as Sawwaq menceritakan kepada kami 'Abdul 'Aziz bin Muhammad menceritakan kepada kami dari 'Amr bi Abi 'Amri dari 'Ikrimah dari Ibnu 'Abbas berkata, Rasulullah saw bersabda barang siapa yang mendapati perbuatan kaum Nabi Luth maka bunuhlah pelaku dan partnernya...

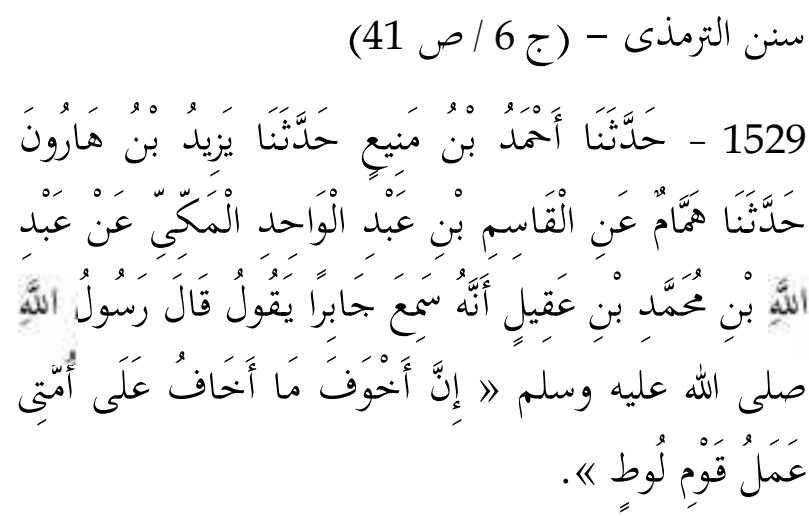

Artinya: Ahmad bin Mani' menyampaikan kepada kami Yazid bin Harun menyampaikan kepad kami Hammam menyapaikan kepada kami dari
al-Qasim bin 'Abdilwahid al-Makii dari 'Abdillah bin Muhammad bin 'Aqil sesungguhnya Jabir mendengar Rasulullah saw bersabda sesunggunya aku takut akan tertimpa musibah umatku karena perbuatan kaum Nabi Luth.

Dalam memahami hadis di atas ditinjau dari agama, Undang-undang/ fatwa MUI dan dari ilmu sosiologi berikut ini: Dalam penjelasan kitab tuhfa al-ahwaz lebih merinci pendapat ulama mengenai hukuman bagi pelaku LGBT. (Abu al Ala Muhammad bin Abdurrahim al Mubarakufi, t.th.: 1364)

(1) Dibunuh; sebagaimana terdapat dalam kandungan hadis sunan ibn Majah no 2658, musnad Ahmad 2779, sunan Abi Dawud no 4464, sunan at tirmidzi no 1528. Dianut oleh sahabat-sahabat Nabi saw, an-Nasir dan Qasim bin Ibrahim serta Imam asy Syafi'i dan Al-Imam AsySyaukani Rahimahullah.

Meskipun kelompok pertama ini sepakat untuk menetapkan hukum bunuh bagi pria pelaku homoseks, mereka berbeda pendapat tentang teknis pelaksanaannya. Abu Bakar as-Siddiq dan Ali bin Abi Thalib berpendapat bahwa mereka harus dihukum pancung, kemudian mayatnya dibakar karena begitu besarnya kemaksiatan yang telah mereka lakukan. Menurut riwayat alMunziri (w.556H), pelakunya dibakar, Abdullah bin Zubair (w.73H/692 M), dan Hisyam bin Abdul Malik (w.126H/743M), Umar bin al Khatab dan Usman bin Affan berpendapat bahwa pelakunya cukup dikurung sampai meninggal dunia. Namun Ibnu Abbas berpendapat bahwa hukuman yang diberikan harus lebih berat sehingga dapat memberikan pelajaran agar masyarakat tidak lagi 
melakukannya. Abu Bakar Muhammad bin Syihab az-Zuhri (tabi' in), Imam Malik dan Imam Ahmad bin Hanbal berpendapat bahwa hukumannya adalah rajam. (Abu al Ala Muhammad bin Abdurrahim al Mubarakufi, t.th.: 1364)

(2) Diberlakukan had (hukuman) zina yaitu hukuman cambuk/hukuman rajam; terdapat dalam sunan Ibn Majah no 2659, Musayyab (w.94H), Ata bin Abi Rabah (w.114H), Hasan, Abu Qatadah (w.118H), an-Nakha'i, Sufyan as-Sauri, Abdurrahman al-Auza'i, Abi Talib, Imam Yahya dan sebagian ulama Mazhab Syafi'i, hukuman terhadap pelaku homoseks sesama pria itu sama dengan hukuman (had) zina. Mereka berpendapat bahwa kepada pelakunya diberlakukan hubungan zina, yaitu dicambuk bagi yang masih bujangan dan dirajam dilempar dengan batu sampai wafat) bagi mereka yang sudah menikah. Argumentasi yang mereka ajukan adalah bahwa perbuatan homoseks dalam bentuk liwat/sodomi itu termasuk dalam kategori perbuatan zina.

(3) Diserahkan kepada penguasa untuk menetapkan hukumannya (takzir). Abu Hanifah memandang perilaku homoseksual cukup dengan ta'zir. Hukuman jenis ini tidak harus dilakukan secara fisik, tetapi bisa melalui penyuluhan atau terapi psikologis agar bisa pulih kembali. Bahkan, Abu Hanifah menganggap perilaku homoseksual bukan masuk pada definisi zina, karena zina hanya dilakukan pada vagina (qubul), tidak pada dubur (sodomi) sebagaimana dilakukan oleh kaumhomoseksual. Pendapat ini dianut oleh Imam Abu Hanifah, Mu'ayyad Billah, dan al-Murtada, keduanya ahli fikih Syiah. Penguasalah yang berhak menetapkan jenis hukumannya, karena perbuatan tersebut tidak dapat dikategorikan ke dalam perbuatan zina, maka hukumannya pun tidak dapat disamakan dengan hukuman zina.

Sedangkan bagi para pelaku lesbian, hukumannya adalah ta'zir. Menurut Sayid Sabiq yang mengutip pendapat Al-Imam Malik Rahimahullah berpendapat bahwa wanita yang melakukan sihaq, hukumannya dicambuk seratus kali. Jumhur ulama berpendapat bahwa wanita yang melakukan sihaq tidak ada hadd baginya, hanya saja ia di-ta'zir, karena hanya melakukan hubungan yang memang tidak bisa dengan dukhul (menjima'i pada farji), dia tidak akan di-hadd sebagaimana lakilaki yang melakukan hubungan dengan wanita tanpa adanya dukhul pada farji, maka tidak ada had baginya. Dan ini adalah pendapat yang rojih (yang benar).

Lesbianisme adalah wanita yang melakukan lesbianisme atau homoseks sesama wanita diberi ganjaran hukuman kurungan dalam rumah sampai mereka menemui ajalnya (Q.S. [4]: 15). Ulama fiqh sepakat untuk mengharamkan perbuatan lesbian berdasarkan hadis: "seorang lakilaki tidak boleh melihat aurat laki-laki, perempuan tidak boleh melihat aurat perempuan dan janganlah seorang lakilaki berada dalam satu kain dengan lakilaki lainnya, dan jangan pula seorang perempuan berada dalam satu kain dengan perempuan lainnya. (HR Ahmad bin Hanbal, Abu Dawud dan at Tirmidzi). Ulama Syiah juga berpendapat bahwa lesbianisme tidak dapat dikategorikan dalam perbuatan zina, karena lesbianisme tersebut adalah perbuatan asyik-masyhuk antara seorang wanita dengan wanita lainnya (mubasyarah), maka hukumnya diserahkan kepada penguasa (takzir), bukan termasuk hudud (jarimah). (Abu al 
Ala Muhammad bin Abdurrahim al Mubarakufi, t.th.: 1364)

Pelarangan LGBT juga bertetangan dengan kaidah figh yang menyatakan, al ashl fi al ibad at tahrim (hubungan seks pada dasarnya adalah haram) sehingga ada sebab-sebab yang jelas dan yakin tanpa keragu-raguan yang menghalalkannya, yakni adanya akad nikah.

Menurut Imam Nawawi al-Bantani (w.1314H/1897M; Mufasir Indonesia asal Banten) juga mengelompokkan homoseks sesama pria ke dalam perbuatan zina. Hal ini terutama dikaitkan dengan surah alMu'minun (23) ayat 5-7. Dalam ayat ini dan ayat sebelumnya, Allah swt telah menjelaskan bahwa kebahagiaan seseorang hamba Allah swt itu amat tergantung pada pemeliharaan kemaluannya dari berbagai penyalahgunaan supaya tidak termasuk orang-orang yang tercela. Menahan ajakan hawa nafsu jauh lebih ringan daripada menanggung akibat buruk dari perbuatan zina/homoseks tersebut. Allah swt telah memerintahkan Rasulullah saw agar menyampaikan perintah itu kepada umatnya agar mereka menjaga pandangannya dengan cara memejamkan mata dan memelihara kemaluannya (Q.S. [24]: 30). Dan juga bertentangan dengan tujuan pernikahan (Q.S. [4]: 1)

Kebutuhan biologis manusia berupa kepuasan seksual bagi Islam bukanlah sekedar watak manusiawi yang tanpa makna. Sebagai makhluk individu maupun sosial, manusia diciptakan Allah dilengkapi dengan dua kekuatan mendasar, yaitu kekuatan berpikir (quwwah nazhariah) dan kekuatan fisik (quwwah 'amaliyah). Allah juga memberikan berbagai taklifat (tanggung jawab) agar manusia mampu meningkatkan kualitas dan kesempurnaan hidupnya. Dalam hal ini manusia bukan hanya menghadapi tuntutan rasio berupa ilmu, atau tuntutan fisik berupa pemenuhan sandang, papan, dan pangan. Ada juga tuntutan kesehatan jasmani dan ruhani. (Sahal Mahfudh. 90)

Menurut Hasbi liwath (homoseks) ialah orang lelaki mensetubuhi dubur orang lelaki. Lazimnya dilakukan terhadap anak-anak muda. Syara' menegah perbuatan liwath ini serta menamainya fahisyah, karena perbuatan ini suatu perbuatan yang sangat mesum; suatu perbuatan yang sangat jijik. Tidak saja lelaki yang melakukan dipandang orang yang rusak secara moral, bahkan orang yang dijadikan korban dipandang orang yang tidak mengetahui harga kemanusiaannya. Apabila liwath ini telah tersebar dalam sesuatu masyarakat, akibatnya kuranglah terjadi perkawinan dan kuranglah perhatian lelaki kepada kaum wanita (para isteri). Menurut nas Alquran hendaklah yang berwajib menjatuhkan hukuman yang disepakati umat terhadap peliwath, yang dapat mengecutkannya. Dan dihubungkan dengan pekerjaan yang mesum ini, pekerjaan menyetubuhi dubur binatang untuk memuaskan nafsu. Sebenarnya, menyetubuhi dubur binatang lebih keji dan lebih buruk dari pada mewathak dubur manusia. Orang yang melakukannya harus ditakzirkan oleh orang yang berwajib. Dan disamakan dengan liwath ini, hukum sihaq (musahaqah), yakni para wanita melakukan hubungan sex sesama wanita (lesbian). Dan dipandang perbuatan yang tidak baik, menikmati sex dengan alat buatan (berbentuk vagina atau penis). (Teungku 
Muhammad Hasbi ash-Shiddieqy, 1998: 364).

Homoseks dalam bentuk liwat termasuk dalam tindak pidana berat, dosa besar, perbuatan keji, perbuatan yang merusak kepribadian, merusak moral dan merusak agama (Q.S. [7]: 80-81). Islam sangat membenci homoseks demikian shingga hukumannya sangat berat diberikan kepada pelakunya. Akibat dari homoseks ini sangat jelek bagi kehidupan pribadi dan masyarakat, di antaranya adalah benci terhadap wanita, melemahnya daya tahan tubuh, terganggunya jiwa dan pikiran serta munculnya berbagai penyakit. Ulama fikih sepakat menyatakan bahwa homoseks dalam bentuk liwat/sodomi hukumnya haram. (Tim. 563)

Sedangkan Sihaaq (lesbian) adalah hubungan cinta birahi antara sesama wanita dengan image dua orang wanita saling menggesek-gesekkan anggota tubuh (farji') nya antara satu dengan yang lainnya, hingga keduanya merasakan kelezatan dalam berhubungan tersebut. (Sayyid Sabiq, t.th.: 51)

Tokoh yang melarang LGBT; Ketua MPR Zulkifli Hasan "LGBT saya menolak. Itu penyimpangan. Jangan (LGBT) diperalat menjadi gerakan. Ini menyangkut keselamatan generasi muda kita. Saya katakan itu menyimpang. Pemerintah harus tegas,". Menurut dia, pemerintah harus segera mengambil sikap atas munculnya gerakan LGBT dan masyarakat harus menolaknya. "Kita harus bersikap. Gerakan (LGBT) harus kita tolak karena melanggar hukum," kata dia. Sebelumnya, Majelis Ulama Indonesia (MUI) juga menegaskan menolak segala bentuk propaganda, promosi, dan dukungan terhadap legislasi dan perkembangan Lesbian, Gay, Biseksual, dan Transgender (LGBT) di Indonesia.

Ketua Umum MUI KH Maruf Amin mengatakan aktivitas LGBT bertentangan dengan Pancasila sila pertama dan kedua, UUD 1945 Pasal 29 ayat (1), dan Pasal 28 J serta UU No 1 thn 1974 tentang Perkawinan. Selain itu, aktivitas LGBT juga bertentangan dengan Fatwa MUI Nomor 57 Tahun 2014 tentang lesbian, gay, sodomi, dan pencabulan. (http: www.//Lia Wanadriani) Dikatakan juga MUI siap merehabilitasi pengidap LGBT.

Abdul Muiz Ghazali, (seorang peneliti studi Islam, Dosen dan peneliti pluralisme di Institut Studi Islam Fahmina (ISIF) Cirebon menyatakan dia mendukung LGBT, dan selama enam tahun terakhir melakukan pendampingan terhadap komunitas LGBT di Cirebon dan Yogyakarta. http://www.bbc.com/indonesia/ majalah/trensosial muslim lgbt.). Pada awalnya anti terhadap orang-orang lesbian, gay, biseksual, dan transgender (LGBT), namun keputusannya untuk mendengar dan mengenal orang-orang dalam komunitas ini kemudian mengubah pandangannya. menyatakan bahwa misalnya dalam teks Alquran disebutkan ada orang yang memang tidak memiliki hasrat seksual terhadap lawan jenisnya. Itu yang menjadi dasarnya, bahwa ini memang diakui dalam Islam. Menurutnya karena ada tafsir ajaran Islam yang saat ini terlalu didominasi oleh pandangan orangorang heteroseksual sehingga LGBT tidak menemukan tempat dalam agama. Dari pendalamannya terhadap tekstual dalam teks-teks agama yang saya pahami, baik itu Alquran, hadis, atau pendapatpendapat ulama yang lain, dan itu sangat mencengangkan. Misalnya kalau homo dihubungkan dengan liwat / sodom itu 
keliru. Tidak selamanya homo pelaku sodom dan itu jelas banyak di teks-teks agama.

Pendapat senada dikemukakan oleh Aan Anshori (http.www.aananshori) menurutnya bahwa semua berjalan sebagaimana kehendak Tuhan. Kenapa Tuhan dibawabawa? Iya, sebab Dia sendiri yang telah memberikan kode suci bahwa individu seperti Anas dan Intan adalah suatu keniscayaan. Sekuat apapun ketidaksetujuan kita terhadap tafsir sebuah ayat Alquran al-Nur 31, kita perlu rendah hati mengakui bahwa Tuhan sangat mungkin menggolongkan Anas sebagai 'ulil irbakh min al-rijal', yakni laki-laki yang tidak punya hasrat (seksual) terhadap perempuan. Jaringan Islam Liberal yang diwakili Khoirul Anwar menegaskan bahwa tidak ada ayat Alquran yang secara eksplisit menolak lesbian, gay, biseksual, transgender pun sebaliknya tidak ada ayat yang menerimanya. Bahwa ayat Alquran yang menceritakan kaum nabi Luth bukan pelarangan namun sebagai "cerita penghibur" berisi pesan menguatkan mental Nabi Muhammad Saw dalam berdakwah yang ditolak kaum Quraisy. (http. www / / Khairul Anwar.)

LGBT dalam bingkai pemberlakuan hukuman dalam Islam yang bertujuan untuk menjadikan manusia selayaknya manusia dan menjaga kelestarian masyarakat. Tujuan-tujuan luhur ditegakkannya Syariat Islam mencakup; pemeliharaan atas keturunan (al muhafazhatu 'ala an nasl), pemeliharaan atas akal (al muhafazhatu 'ala al 'aql), pemeliharaan atas kemuliaan (al muhafazhatu 'ala al karamah), pemeliharaan atas jiwa (al muhafazhatu 'ala an nafs), pemeliharaan atas harta (al muhafazhatu 'ala an al maal), pemeliharaan atas agama (al muhafazhatu 'ala al diin), pemeliharaan atas ketentraman/keamanan (al muhafazhatu 'ala al amn), pemeliharaan atas negara (al muhafazhatu 'ala al daulah), maka LGBT dilarang.

LGBT dilarang sebagaimana Majelis Ulama Indonesia (MUI) pada bulan Desember 2014 telah mengeluarkan fatwa nomor 57 tahun 2014 tentang Lesbian, Gay, Sodomi dan Pencabulan dalam ketentuan hukumnya berbunyi 1 . Hubungan seksual hanya dibolehkan bagiseseorang yang memiliki hubungan suami isteri, yaitu pasangan lelaki dan wanita berdasarkan nikah yang sah secara syar'i. 2. Orientasi seksual terhadap sesama jenis adalah kelainan yang harus disembuhkan serta penyimpangan yang harus diluruskan. 3. Homoseksual, baik lesbian maupun gay hukumnya haram, dan merupakan bentuk kejahatan (jarimah). 4. Pelaku homoseksual, baik lesbian maupun gay, termasuk biseksual dikenakan hukuman had dan/atau ta'zir oleh pihak yang berwenang. 5. Sodomi hukumnya haram dan merupakan perbuatan keji yang mendatangkan dosa besar (fahisyah). (Fatwa MUI Nomor 57 tahun 2014). MUI sebenarnya bukan kali ini saja membuat fatwa yang semangatnya homophobia (membenci homoseksual), pada 11 Oktober 1997 MUI juga mengeluarkan sebuah fatwa tentang "Kedudukan Waria" yang berisi bahwa Waria sebagai sesuatu yang haram yang diharuskan "dikembalikan" menjadi lakilaki yang dianggap "normal".

Fatwa MUI di atas sejalan dengan peraturan lain seperti dalam Kitab Undang-undang Hukum Pidana (terjemahan resmi Wetnoek Van Strafrecht) 
dan pasal 292 yang secara eksplisit mengatur soal sikap tindak homoseksual, yang dikaitkan dengan usia di bawah umur. Isi pasal itu adalah sebagai berikut: “Orang dewasa yang melakukan perbuatan cabul dengan orang lain sesama kelamin, yang diketahuinya atau sepatutnya harus diduganya belum dewasa, diancam dengan pidana penjara paling lama lima tahun." Pasal 4 butir 1a UU Pornografi menyatakan: "persegamaan, termasuk persegamaan yang menyimpang", dengan penjelasan yang termasuk menyimpang antara lain"persegamaan dengan mayat, bintang, oral seks, anal seks, lesbian dan homoseksual. Dan juga bertentangan dengan pasal 1 Undang Undang No. 1 Tahun 1974 mengenai perkawinan bahwa "Perkawinan ialah ikatan lahir bathin antara seorang pria dengan seorang wanita sebagai suami isteri dengan tujuan membentuk keluarga (rumah tangga) yang bahagia dan kekal berdasarkan Ketuhanan Yang Maha Esa".

Meskipun dalam UU RI No 39 Tahun 1999 tentang Hak Asasi Manusia secara lebih dalam mengatur mengenai kebebasan berekpresi tersebut, dalam Pasal 22 Ayat (3) UU tersebut menyebutkan bahwa "Setiap orang bebas mempunyai, mengeluarkan, dan menyebarluaskan pendapat sesuai hati nuraninya, secara lisan atau tulisan melalui media cetak maupun media cetak elektronik dengan memperhatikan nilainilai agama, kesusilaan, ketertiban, kepentingan umum, dan keutuhan bangsa".

Uraian di atas akan menegaskan kembali bahwa gerakan LGBT tidak ada tempat di bumi nusantara, memperlakukan mereka dengan manusiawi bukan berarti akan menerima eksistensinya di mata hukum, artinya terkait dengan aturan dalam agama Islam yaitu warisan, pernikahan, dan nasab karena akan berubah besaran warisan, status, kewajiban dan hak dalam pernikahan, nasab. Sanksi untuk mereka diberikan sesuai dengan aturan yang berlaku di Indonesia.

\section{PENUTUP}

Keberadaan LGBT di Indonesia dalam sejarahnya telah ada menurut Snouck di sebagian daerah penerimaannya ditolak dan ada yang diabaikan. Dari Aceh, Jawa Tengah, Sulawesi yang dikenal dengan kaum bissu bahkan Ponorogo dengan segala ritual dan merasuk kepada kesenian rakyat. Pada masa modern gaya hidup LGBT lebih beragam dan membuat kelompokkelompok tertentu yang sampai sekarang berupaya agar keberadaannya diakui oleh masyarakat dan menuntut pemerintah untuk terlibat. Meskipun begitu, mayoritas umat Islam di Indonesia menolak karena bertentangan dengan dogma agama, UU Perkawinan; tujuan, dan definisi dari suami-isteri, strata sosial masyarakat, bertentangan dengan fatwa MUI, tokoh-tokoh seperti ketua MPR, tokoh semua agama yang diakui di Indonesia dan seterusnya.

Gaya hidup LGBT dijelaskan akan mendapat laknat, Figh al-hadis tentang sanksi atau hukuman ada perbedaan di antara ulama; hukum bunuh yang dianut oleh sahabat an-Nasir dan Qasim bin Ibrahim serta Imam asy Syafi'i sedangkan teknisnya juga terdapat perbedaan pendapat. Hukum rajam, menurut Imam asy-Syafi'i pelaku liwat yang laki-laki harus dirajam tanpa membedakan apakah pelakunya itu masih bujangan atau sudah 
menikah. hukumannya sama dengan hukuman berzina. Pendapat ini seperti ini disampaikan oleh Sa'id bin Musayyab, Atha' bin Abi Rabbah, Hasan, Qatadah, Nakha'i, Tsauri, Auza'i, Imam Yahya dan Imam Syafi'i (dalam pendapat yang lain), mengatakan bahwa hukuman bagi yang melakukan liwath sebagaimana hukuman zina. Diserahkan kepada penguasa (takzir), pendapat ini dianut oleh Imam Abu Hanifah, Mu'ayyad Billah, dan alMurtada, keduanya ahli fikih Syiah. Penguasalah yang berhak menetapkan jenis hukumannya, karena perbuatan tersebut tidak dapat dikategorikan ke dalam perbuatan zina, maka hukumannya pun tidak dapat disamakan dengan hukuman zina. Perbedaan ini terjadi karena perbedaan redaksi/matan hadis.

Kemajuan zaman tidak bisa dibendung, tugas umat Islam semakin berat dalam upaya melakukan amar makruf dan nahi munkar tanpa henti. Tidak bisa hanya duduk diam tanpa melakukan sesuatu kegiatan dalam bentuk apapun yang tidak sesuai dengan syari'at harus ditolak.

\section{DAFTAR KEPUSTAKAAN}

al Mubarakufi, Abu al Ala Muhammad bin Abdurrahim. t.th. Tuhfah alAhwaz Syarah Jami' at-Tirmidzi. Jilid 1. Jordan: Bait al-Afkar al-Dauliyah.

Ali bin Abdul Aziz Musa. 2006. Kekejian Perilaku Kaum Nabi Luth. Jakarta: CENDEKIA Sentra Muslim.

Alimi, Moh. Yasir. 2004. Dekonstruksi Seksualitas Poskolonial: dari Wacana Bangsa Hingga Wacana Agama. Yogyakarta: LkiS Yogyakarta.
ash-Shiddieqy, Teungku Muhammad Hasbi. 1998. Al-Islam. Semarang: Pustaka Rizki Putra.

Bungin, Burhan (ed). 2007. Metodologi Penelitian Kualitatif Aktualisasi Metodologis ke Arah Ragam Varian Kontemporer.

Fajar, Mukti dan Yulianto Achmad. 2010. Dualisme Penelitian Hukum Normatif dan Empiris. Yogyakarta: Pustaka Pelajar.

Fatwa MUI Nomor 57 tahun 2014 Tentang Lesbian, Gay, Sodomi, dan Pencabulan.

Hanafi, Agustin. Mewaspadai Aliran LGBT di Aceh. Serambi Opini. 11 Februari 2016.

Hurgronje, Snouck. 1985. Aceh Di Mata Kolonialis (The Achehnese). Jilid II. Jakarta: Yayasan Soko Guru.

Husna, Asmaul. LGBT Berjubah Demokrasi. Serambi Opini. 11 Februari 2016

Lathief, Halillintar. 2004. Bissu Pergulatan dan Peranannya di Masyarakat Bugis. Makasar: DESANTARA.

Mahfudh, Sahal. 2007. Nuansa Fiqih Sosial. Yogyakarta: LkiS Printing Cemerlang Yogyakarta.

------. 2004. Nuansa Fiqih Sosial. Yogyakarta: LkiS Yogyakarta.

Marzuki, Peter Mahmud. 2013. Penelitian Hukum Edisi Revisi. Jakarta: Kencana.

Rofiq, Ahmad. 2004. Figh Kontekstual dari Normatif ke Pemaknaan Sosial. Yogyakarta: Pustaka Pelajar.

Sabiq, Sayyid, t.th. Figh al-Sunnah, Juz 4, 
Salim, Fahmi. 2013.Tafsir Sesat 58 Essai Kritis Wacana Islam di Indonesia. Jakarta: Gema Insani.

Soekanto, Soerjono. 2004. Sosiologi Keluarga Tentang Ikhwal Keluarga Remaja dan Anak. Jakarta: Rineka Cipta.

------. 2012. Pengantar Penelitian Hukum. Jakarta: Universitas Indonesia (UIPress).

Software Maktabah Syamilah

Suryakusuma, Julia. 2012. Agama, Seks dan Kekuasaan. Jakarta: Komunitas Bambu.

Tim. 2006. Eksiklopedi Hukum Islam. Jilid 2. Jakarta: Ichtiar Baru Van Hoeve.

Tim. 2008. Kamus Besar Bahasa Indonesia. Jakarta: Gramedia Pustaka Umum.

Wieringa, Saskia E., dkk. 2007. Hegemoni Hetero-Normativitas Membongkar Seksualitas Perempuan yang Terbungkam. Jakarta: Kartini Network.
Yanggo, Huzaimah Tahido. 2005. Masail Fiqhiyah Kajian Hukum Islam Kontemporer. Bandung: Angkasa Bandung.

Internet/Koran

http: www//Lia Wanadriani Santosa. Zulkifli Hasan tegaskan tolak gerakan LGBT.htm

http: www//Aan Anshori. Apakah Homoseksual Masuk Surga.html

http: www/ / Nasrullah el-Jabouny. Sikap kita terhadap Keberadaan kaum LGBT..htm

http://www.bbc.com./ Abdul Muiz Ghazali. Trensosial Muslim Lgbt.

http: www//Khairul Anwar. LGBTDalamAl-QuranIslamLib.htm

http: www//Abba Gabrillin. MUI dan Ormas Islam: LGBT Haram.htm. 